\title{
An Insight of Vitamin $\mathbf{E}$ as Neuroprotective Agents
}

\author{
${\text { Hui-Min } \text { Yap }^{1 *} \text { and Kwan-Liang Lye }}^{1}$ \\ ${ }^{1}$ Department of Biomedical Sciences Faculty of Medicine and Health Sciences, Universiti Putra Malaysia, 43400 UPM \\ Serdang, Selangor Darul Ehsan, Malaysia
}

\begin{abstract}
Nervous system is the network of nerve cells that transmits nerve impulses throughout the body. It is rich in both unsaturated fats and irons, making it predominantly susceptible to oxidative stress and damage. Oxidative stress reflects the disruption of the redox balance between the formation and clearance of highly free radicals, for instance reactive oxygen species (ROS) and reactive nitrogen species (RNS). Oxidative stress will further damage the cell lipid, protein and DNA. Oxidative stress has a role in the modulation of critical cellular functions, such as apoptosis program activation, ion transport and calcium mobilization which lead to cell death. Many studies were conducted to prevent neuronal cell death caused by oxidative stress through administration of free radical scavenging antioxidant, such as vitamin E. Vitamin $\mathrm{E}$ is known as a chain-breaking antioxidant that showed the capability to increase the viability of neuronal cells that had undergone glutamate injury by inhibiting glutamate-induced pp60 (c-Src) kinase activation. Vitamin E occurs in 8 forms, namely $\alpha$-, $\beta$-, $\gamma$ - and $\delta$-tocopherols and $\alpha-, \beta-, \gamma$-and $\delta$-tocotrienols. Tocotrienols differ from tocopherols by possessing an unsaturated isoprenoid side chain instead of a saturated phytyl tail. Tocotrienols, compared to tocopherols, are lightly studied due to the abundance of $\alpha$-tocopherol in the human body and its antioxidant properties. Nevertheless, recent studies showed that $\alpha$-tocotrienol is more effective in preventing lipid peroxidation compared to $\alpha$-tocopherol. Furthermore, tocotrienol was discovered to protect neuronal cell through antioxidant-independent activities. The tocotrienol-rich fraction (TRF) is an extract that consists of $75 \%$ tocotrienol and 25\% $\alpha$-tocopherol. TRF was reported to possess potent antioxidant, anti-inflammation, anticancer and cholesterol-lowering properties. Thus, this writing highlights the significant neuroprotective effects of tocotrienol and tocopherol.
\end{abstract}

Keywords: neuroprotective agents; vitamin E; oxidative stress; tocotrienols; tocopherols.

Received: $10^{\text {th }}$ March 2020

Accepted: $12^{\text {th }}$ April 2020

Published Online: $21^{\text {th }}$ April 2020

*Correspondence: Hui-Min Yap, Department of Biomedical Sciences Faculty of Medicine and Health Sciences, Universiti Putra Malaysia, 43400 UPM Serdang, Selangor Darul Ehsan, Malaysia; huimin050686@gmail.com.

Citation: Yap, H-M. \& Lye, K-L. An insight of vitamin E as neuroprotective agents. Prog Mircobes Mol Bio1 2020; 3(1): a0000071. https://doi.org/10.3687/pmmb.a0000071

\section{INTRODUCTION}

\begin{abstract}
Antioxidant
It known that aerobic organisms have developed a series of defense mechanisms, which involve antioxidants, in response to free radical production in order to maintain free radicals' level compatible with cellular functions and metabolic processes ${ }^{[1]}$. Antioxidant defense mechanism can be classified into enzymatic and non-enzymatic. The enzymatic defense mechanism includes superoxide dismutase (SOD), GSH peroxidase (GPx) and catalase (CAT), whereas non-enzymatic antioxidant defenses include vitamin $\mathrm{E}$, ascorbic acid (vitamin C), glutathione (GSH) and other antioxidants ${ }^{[2]}$.
\end{abstract}

\section{GLUTATHIONE (GSH)}

Glutathione (GSH) is the main thiol antioxidant and redox buffer of the cell ${ }^{[3,4]}$. It is a tripeptide comprised of glutamate, glycine and cysteine. It is synthesized in the cytosol by 2 enzymes that utilize ATP, that is GSH synthetase and gamma-glutamylcysteine ( $\gamma$-GluCys) synthetase ${ }^{[5]}$. The gamma-glutamylcystein synthetase forms dipeptide gamma-glutamylcysteine by utilizing cysteine and glutamate as substrates. Gamma-glutamylcysteine is then merged with glycine in a reaction catalyzed by GSH synthetase thus forming GSH. GSH production is controlled by feedback inhibition of the $\gamma$-GluCys synthetase reaction by the end product $\mathrm{GSH}^{[6]}$. Total GSH in the cells can be free or bound to protein. The free GSH is present in reduced form, which will be converted to the oxidized form (GSSG) during oxidative stress and can be restored to the reduced form by the action of glutathione reductase $(\mathrm{GR})^{[7]}$. The oxidation-reduction pathway of GSH is shown in Figure 1. 


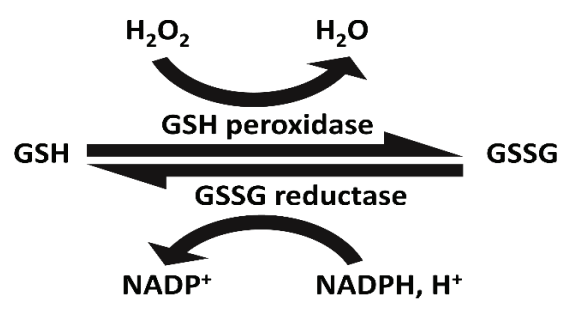

Figure 1. Oxidation-reduction pathway of reduced glutathione (GSH) and oxidized glutathione (GSSG).

GSH exerts its protection against oxidative stress by several approaches. Firstly, GSH directly scavenges reactive hydroxyl free radicals, ROS and radical centers on DNA and other biomolecules. Also, GSH functions as the cofactor for several detoxifying enzymes, for instance glutathione-S-transferases (GSTs) and glutathione peroxidase (GPx), which are vital in protection against oxidative stress. GPx is an enzymatic antioxidant which is predominantly responsible for the intracellular reduction of hydrogen peroxide $\left(\mathrm{H}_{2} \mathrm{O}_{2}\right)$ to water with the support of GSH as electron donor ${ }^{[8]}$. Thus, GSH is oxidized to glutathione disulfide (GSSG) through GPx activity and quickly restored to GSH by the reaction catalyzed by glutathione reductase (GR). Whereas, glutathione-S-transferases conjugate GSH to free radicals, for instance hydrogen peroxides, thus reducing the deleterious interactions between free radical and essential cellular components ${ }^{[9,10]}$. Furthermore, GSH provides reducing capacity for the formation of deoxynucleotides by ribonucleotide reductase, the reduction of dehydroascorbate to ascorbate and restoration of vitamin $\mathrm{E}$ from radical form ${ }^{[2,11]}$.

Also GSH has been suggested to function as neurohormone based on the presence of extracellular GSH in brain, the release of GSH from brain slices upon stimulation, the specific binding of GSH to extracellular receptors and the induction of sodium currents in neocortex, and the stimulation of a signal cascade in astrocytes $^{[12,13]}$. Furthermore, some studies suggested that astrocytes support neuronal cells by means of providing GSH and cysteinylglycine (CysGly), which is the GSH precursor to neuronal cells ${ }^{[6]}$.

\section{VITAMIN E}

Vitamin E is a lipid-soluble vitamin vital for human nutrition and health. The term 'vitamin E' was first introduced by Evans and Bishop (1922) ${ }^{[14]}$ in describing a dietary factor in rat reproduction. The vitamin $\mathrm{E}$ family includes 8 different isomers, namely $\alpha-, \beta-, \gamma-$, and $\delta$-tocopherols and $\alpha-, \beta-, \gamma-$, and $\delta$-tocotrienols. Tocopherols and tocotrienols, as a group known as tocochromanols comprise of a chromanol ring system and a polyprenyl side chain. The 8 isomers of vitamin $\mathrm{E}$ vary in the degree of antioxidant and biological activities. All tocochromanols are amphipathic molecules, with the lipophilic isoprenoic side chain of tocochromanol is anchoring the membrane lipids, whereas the polar chromanol ring is exposed to the membrane surface ${ }^{[15]}$.
Vitamin E is the major component that present amongst the lipid elements of cell membranes and lipoproteins ${ }^{[16]}$. Vitamin E is exclusively synthesized by photosynthetic eukaryotes and other oxygenic photosynthetic organisms for instance cyanobacteria. Therefore, vitamin $\mathrm{E}$ is ingested along with fat-containing food, like nut oil seeds, egg yolk, vegetable oils, margarine, soya bean, wheat, avocados and germ $^{[15]}$.

Vitamin $\mathrm{E}$ has numerous biological functions. The pharmacologic use of vitamin $\mathrm{E}$, in doses 10 to 50 times the daily requirement, was recommended in 1947 for the treatment of an array of cardiovascular disorders ${ }^{[17]}$. The chain-breaking antioxidant properties of vitamin $\mathrm{E}$ was detected in the 1950 s and consequently proved to be useful in preventing lipid peroxidation by scavenging chain-carrying peroxyl radicals and generates an induction period $^{[18,19,20]}$. Furthermore, studies reported that severe vitamin E deficiency in human will leads to neuromuscular abnormalities because of free radical damage to the nerve cells $^{[21,22]}$. Vitamin E deficiency seldom occurs in human as a result of dietary deficiencies but occurs as a result of genetic abnormalities in the $\alpha$-tocopherol transfer protein $(\alpha-\mathrm{TTP})^{[23]}$. Vitamin E also possesses non-antioxidant functions, with vital role in cellular signaling by regulating protein kinase $\mathrm{C}^{[24]}$. Moreover, vitamin E in combination with selenium were exhibiting ability to prevent loss of spermatogenesis in males ${ }^{[25]}$. Some studies also indicated that vitamin $\mathrm{E}$ prevents most of the glutamate-induced neuronal cell death ${ }^{[26]}$. Furthermore, dietary of vitamin $\mathrm{E}$ can enhance immune responses in numerous animal $\operatorname{models}^{[27]}$

\section{Metabolism of vitamin $\mathbf{E}$}

The hydrophobic nature of vitamin E make it preferentially located in oil storage organs, fat deposits and in cell membranes. It is transported around the body as an element of plasma lipoproteins. After ingestion of dietary vitamin E, it will be absorbed into the enterocyte, followed by packaging into chylomicrons. These nascent chylomicrons are then secreted into the lymphatic circulation. During the chylomicron catabolism in the circulation, the absorbed vitamin $\mathrm{E}$ is transferred to circulating lipoproteins and drained into the bloodstream. The high-density lipoprotein (HDL) in the bloodstream donates apolipoprotein C-II (APOCII) and apolipoprotein E (APOE) to the nascent chylomicron and thus converts it to a mature chylomicron. Lipoprotein lipase (LPL) is bound to the endothelial lining of capillary walls. During the lipolysis by LPL, various form of vitamin $\mathrm{E}$ could be transferred to tissues. Also, vitamin E could be exchanged between HDLs and other circulating lipoproteins, which could deliver vitamin E to the peripheral tissues. The resultant chylomicron remnant from lipolysis are primarily taken up by the liver through the chylomicron remnant receptors ${ }^{[28]}$. In liver, remnant chylomicron-associated vitamin $\mathrm{E}$ is incorporated into nascent very-low density lipoproteins (VLDL) via the action of $\alpha-\mathrm{TTP}^{[29]}$. One of the vital determinants of vitamin $\mathrm{E}$ biological activity is the affinity of its analogues for $\alpha$-TTP. The $\alpha$-TTP has higher preference to $\alpha$-tocopherol compared to other vitamin $\mathrm{E}$ isomers ${ }^{[30]}$. When the VLDL are secreted into the plasma circulation, VLDL are converted into intermediate density lipoprotein (IDL) and low density 
lipoprotein (LDL) via the action of LPL ${ }^{[31,32]}$. Vitamin E is then transferred from plasma to cells through uptake facilitated by receptor-mediated lipoprotein endocytosis, lipid transfer proteins and lipases, and selective lipid uptake $^{[33]}$. Studies demonstrated that LDL receptor were facilitating the tissue incorporation of plasma vitamin $\mathrm{E}$ as part of LDL, while LPL and phospholipid transfer protein enable the tissue incorporation of plasma vitamin $\mathrm{E}$ as part of triglyceride-rich lipoprotein ${ }^{[34-36]}$. Furthermore, IDL and LDL have LDL receptor-binding domains which allow receptor-mediated lipoprotein endocytosis to facilitate uptake of vitamin $\mathrm{E}$ into the peripheral tissue ${ }^{[37]}$. The pathways of vitamin $\mathrm{E}$ absorption and distribution are depicted in Figure 2.

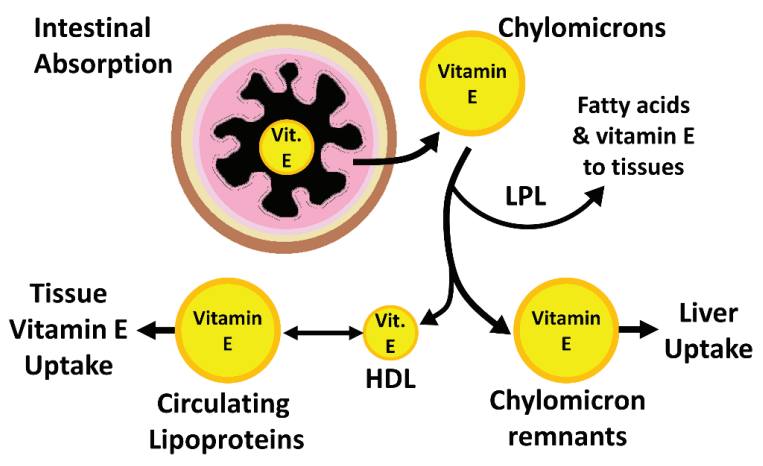

Figure 2. Pathways for vitamin E absorption and distribution.

Vitamin E is one of the most vital lipid-soluble antioxidants that protects membranes from oxidation by reacting with lipid radicals produced in the lipid peroxidation chain reaction $^{[31]}$. As an antioxidant agent, vitamin E does not work independently in scavenging free radicals. It is a part of the redox antioxidant system. Vitamin E is efficiently reduced from its free radical form (tocotrienoxyl or tocopheroxyl) back to its reduced native form via enzymatic or non-enzymatic mechanisms. Vitamin C can directly restore vitamin $\mathrm{E}$ and thiol antioxidant, for instance GSH, and indirectly restore vitamin $\mathrm{E}$ via redox antioxidant network. This system maintains the concentration of vitamin E radicals low. Hence, the loss or consumption of vitamin $\mathrm{E}$ is prevented ${ }^{[38]}$.

\section{ISOMER OF VITAMIN E}

\section{Tocopherol}

Tocopherol contains a chromanol ring and a saturated phytyl side chain ${ }^{[39]}$. The structural formulae of tocopherols are shown in Figure 3. Tocopherol is primarily found in sunflower and olive oils. Among 8 isomers of vitamin E, $\alpha$-tocopherol was firstly derived from wheat germ oil and named in 1936 by Evan et al. ${ }^{[40]}$. The $\alpha$-tocopherol have the highest bioavailability among the isomers because of the recognition of $\alpha$-ТTP ${ }^{[41]}$. The core function of $\alpha$-tocopherol is terminating the chain reaction of lipid peroxidation to inhibit cell membrane and LDL from oxidative disintegration $^{[42]}$. Tocopherol also provides protection against peroxynitrite-induced lipid oxidation. Other than antioxidant function, vitamin $\mathrm{E}$ has functions in cell signaling activities, for instance regulation of protein kinase $\mathrm{C}$, inhibition of cyclooxygenase-2 activity and modulation of phospholipase A2 activity were due to the present of $\alpha$-tocopherol. The $\alpha$-tocopherol could dilate blood vessels and interferes with aggregation of platelets ${ }^{[43]}$. Osakada et $a l .{ }^{[44]}$ reported that $1-10 \mu \mathrm{M} \alpha$-tocopherol effectively protects striatal neurons against cytotoxicity induced by a L-buthionine-S,R-sulfoximine (BSO) via the reduction of oxidative stress. Study indicated that $\alpha$-tocopherol can effectively relieve neuronal damage induced by oxygencentered free radicals ${ }^{[45]}$. Also, $\alpha$-tocopherol functions in regulating inflammation by reducing the release of cytokine interleukin-1 $\beta$ (IL-1 $\beta$ ) via inhibition of 5-lipoxygenase pathway $^{[45]}$.

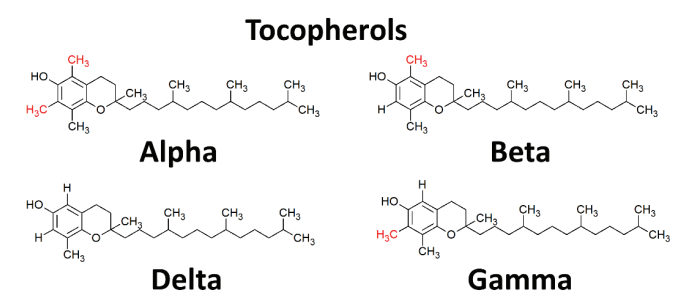

Figure 3. Structural formulae of Tocopherols.

\section{Tocotrienol}

Tocotrienols vary from tocopherols by having 3 double bonds in the hydrophobic tridecyl side chain ${ }^{[42]}$. Figure 4 depicted the structural formulae of tocotrienols. Tocotrienols are rich in barley oil and palm oil. More than $95 \%$ of studies on vitamin $\mathrm{E}$ focusing on $\alpha$-tocopherol due to its richness in the human body and its antioxidant functions. Nevertheless, recent studies exhibited that tocotrienol possesses healthpromoting properties such as vital neuroprotective effect, cholesterol lowering and anti-cancer properties that are usually not displayed by tocopherols ${ }^{[46]}$. Even though tocotrienols have low bioavailability, its antioxidant activity is higher than tocopherols ${ }^{[47]}$. The $\alpha$-tocotrienol exhibited better peroxyl radical scavenging potency than $\alpha$-tocopherol in liposomal membrane ${ }^{[48]}$. The unsaturated side chain of tocotrienol allowing even distribution of tocotrienol in the membrane bilayer that further enhance the interaction of chromanol ring of $\alpha$-tocotrienol with lipid radicals. Tocotrienols also moves between lipid vesicles much faster than $\alpha$-tocopherol. Furthermore, the chromanoxyl radical of $\alpha$-tocotrienol ( $\alpha$-tocotrienoxyl) was to be recycled in membranes and lipoproteins more rapidly compared to $\alpha$-tocopheroxyl radical ${ }^{[49,50]}$.

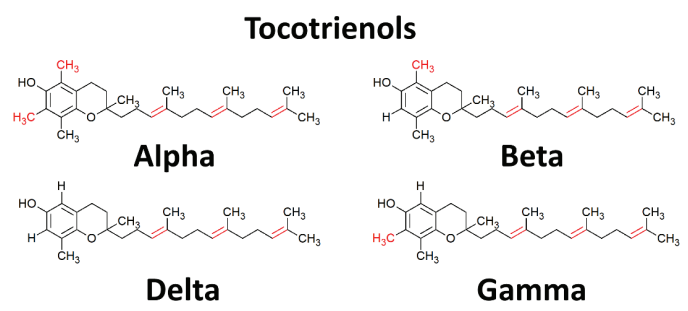

Figure 4. Structural formulae of Tocotrienols. 


\section{FUNTIONS OF VITAMIN E}

\section{Antioxidant}

Vitamin E efficiently inhibits lipid peroxidation and scavenges the chain-propagating peroxyl radical. The scavenging outcome of $\alpha$-tocotrienol was 1.5fold higher than $\alpha$-tocopherol in liposomes ${ }^{[49]}$. Moreover, $\alpha$-tocotrienol was 6.5 times more effective in protecting cytochrome P-450 against oxidative damage. The tocotrienol-rich fraction (TRF) from palm oil is significantly more effective than $\alpha$-tocopherol in inhibiting oxidative damage in rat brain mitochondria induced by ascorbate- $\mathrm{Fe}^{2+}$, the free radical initiator azobis (2-amidopropane) dihydrochloride (AAPH) and photosensitization ${ }^{[51]}$. Furthermore, palm TRF at micromolar concentration providing better protection against copper-induced oxidation of plasma low density lipoprotein and also lipid peroxidation in human umbilical vein endothelial cells (HUVEC), as compared with $\alpha$-tocopherol ${ }^{[52]}$. Moreover, the efficacy of $\alpha$-tocotrienol in protection against $\mathrm{Fe}^{2+} \mathrm{NADPH}-$ induced lipid peroxidation in rat liver microsome was 40 times higher than $\alpha$-tocophero[ ${ }^{[49]}$. This could strongly suggest that $\alpha$-tocotrienol has greater scavenging effect compared to $\alpha$-tocopherol.

\section{Neuroprotection}

Recent studies demonstrated that vitamin $\mathrm{E}$ have health benefit properties which go beyond their known antioxidant activity. Studies indicated that $\alpha$-tocotrienol prevented both oxidative stress-dependent and oxidative stress-independent apoptosis, whereas $\delta$ - and $\gamma$-tocotrienol only inhibited oxidative stress-dependent apoptosis. This displays that neuroprotective effect of $\alpha$-tocotrienol could be mediated via non-antioxidant antiapoptotic actions in addition to its antioxidant property ${ }^{[53]}$. Moreover, nanomolar concentrations of $\alpha$-tocotrienol could block glutamate-induced neuronal cell death, while $\alpha$-tocopherol did not exhibit this property ${ }^{[54]}$. Furthermore, nanomolar concentration of $\alpha$-tocotrienol could protect glutamate-induced cell death in mouse neuroblastoma HT4 cell via inhibition of 12-lipoxygenase and phospholipase $\mathrm{A} 2$ activation that further interfere the state of phosphorylation ${ }^{[2,54,55]}$. Additionally, tocotrienols effectively inhibited the activation of pp60 c-src kinase, a kinase that centrally involved in glutamate-induced cell death ${ }^{[26]}$. For neuroprotection properties, studies reported that other sources (e.g. microbial resources) were also demonstrating strong antioxidants ${ }^{[56-66]}$ and neuroprotective properties ${ }^{[67-72]}$, for instance radical scavenging and metal chelating potentials ${ }^{[73-80]}$.

\section{Other Beneficial Properties of Vitamin E}

Numerous studies indicated that tocotrienols could suppress proliferation and induce apoptosis of several tumor cells such as breast, liver, lung, colon, stomach, skin, pancreas and prostate cancer cells ${ }^{[81-87]}$. The $\gamma$-tocotrienol and $\delta$-tocotrienol were reported to have anti-tumor activity in breast cancer cell irrespective of estrogen receptor status ${ }^{[88,89]}$. The $\gamma$-tocotrienol also prevents cholesterol synthesis by suppressing
3-hydroxy-3-methylglutaryl-CoA reductase activity via a post-transcriptional mechanism ${ }^{[90]}$. The cardioprotective effects of tocotrienol are also facilitated via their ability to suppress inflammation thus reduce the expression of adhesion molecules and monocyte-endothelial cell adhesion $^{[91]}$.

\section{BIOMARKER OF NEURONAL CELL INJURY}

The continuous supply of oxygen and glucose is extremely important for brain energy metabolism. The disruption of this supply for a few minutes can introduces a sequence of biochemical event that lead to cell swelling, leakage and damage leading to neuronal cell death ${ }^{[92]}$. Intracellular components, such as neuron specific enolase (NSE), can be detected in the extracellular fluid and celebrospinal fluid (CSF) upon neuronal damage ${ }^{[93]}$. Among various intracellular proteins, the concentrations of NSE, S100ß, glial fibrillary protein (GFAP) and myelin basic protein (MBP) exhibited positive correlation to the severity of the brain damage ${ }^{[94]}$. The NSE catalyzes the conversion of 2-phospho-D glycerate to phosphoenolpyruvate in glycolytic pathway and localized predominantly in neuronal cytoplasm ${ }^{[95]}$. The level of NSE in the cerebrospinal fluid has been used as markers of neuronal damage in patients with a variety of neurologic condition including status epilepticus and metastatic lung cancer. Furthermore, positive correlation was reported between the glutamate-induced changes of the neuron-specific enolase efflux fraction ${ }^{[06]}$. NSE is highly expressed as a glycolytic enzyme to replenish the ATP supply when energy depletion occurs, which could be due to neurotoxin agents for instance glutamate ${ }^{[97]}$. Meanwhile, $\mathrm{S} 100 \beta$ is a calcium-binding protein localized in astrocytes. The S100 $\beta$ levels were increased after central nervous system lesions. Furthermore, high level of NSE and S100 $\beta$ were reported in the CSF of infants and children after traumatic brain injury ${ }^{[98]}$.

\section{CONCLUSION}

Vitamin E, which made up of tocotrienols and tocopherol isomers, is a known chain-breaking antioxidant. Studies demonstrated that vitamin E have health benefit properties beyond their known antioxidant activity. With the $\alpha$-tocotrienol preventing both oxidative stressdependent and oxidative stress-independent apoptosis, while $\delta$ - and $\gamma$-tocotrienol only inhibited oxidative stress-dependent apoptosis. These findings demonstrated that neuroprotective effect of $\alpha$-tocotrienol could be mediated via non-antioxidant anti-apoptotic actions in addition to its antioxidant property ${ }^{[53]}$. Furthermore, TRF and $\alpha$-tocopherol at concentration of 100 to $300 \mathrm{ng} / \mathrm{mL}$ demonstrated minor prophylactic properties but significant recovery ability in improving the glutamate-injured cell viabilities in both mono-culture and co-culture model. TRF at nanomolar concentration also exhibited better protection to neuronal cell against glutamate toxicity compared to $\alpha$-tocopherol. Therefore, the putative mechanism of TRF and $\alpha$-tocopherol action in protecting and recovering glutamate-injured cells was of great interest and warrant further research. More in vivo studies should be performed 
to further understand the recovery mechanism of TRF and $\alpha$-tocopherol in a complete body system.

\section{Conflict of Interest}

The authors declare that there is no conflict of interest in this work.

\section{Authors Contributions}

The literature review and manuscript writing were performed by H-MY and K-LL.

\section{Reference}

1. Contestabile, A. Oxidative stress in neurodegeneration: Mechanisms and therapeutic perspectives. Curr Top Med Chem, 2001; 1(6): 553-568.

2. Valko, M, Leibfritz, D, Moncol, J, et al. Free radicals and antioxidants in normal physiological functions and human disease. Int J Biochem Cell B, 2007; 39: 44-84

3. Koike, Y, Hisada, T, Utsugi, M, et al. Glutathione redox regulates airway hyperresponsiveness and airway inflammation in mice. Am J Respir Cel Mol Biol, 2007; 37(3): 322-329.

4. Derick, H, Nanawa, N, Saberi, B, et al. Mechanisms of liver injury. III. Role of glutathione redox status in liver injury. Am J Physiol Gastrointest Liver Physiol, 2006; 291(1): 1-7.

5. Peters, WHM, Schaik, AV, Peters, JH, et al. Oxidised- and total non-protein bound glutathione and related thiols in gallbladder bile of patients with various gastrointestinal disorders. BMC Gastroenterol, 2007; 7(7).

6. Dringen, R. Metabolism and functions of glutathione in brain. Prog Neurobiol, 2000; 62: 649-671.

7. Bains, JS and Shaw, CA. Neurodegenerative disorders in humans: The role of glutathione in oxidative stress-mediated neuronal death. Brain Res Rev, 1997; 25: 335-358.

8. Lubos, E, Loscalzo, J, and Handy, DE. Glutathione peroxidase-1 in health and disease: From molecular mechanisms to therapeutic opportunities. Antioxid Redox Signal 2011; 15(7): 1957-1997.

9. Josephy, PD. Genetic variations in human glutathione transferase enzymes: Significance for pharmacology and toxicology. Hum Genom Proteom, 2010; 2: 1-16.

10. Bladeren, PJ. Glutathione conjugation as a bioactivation reaction. Chem Biol Interact 2001; 129(1-2): 61-76.

11. Pastore, A, Federici, G, Bertini, E, et al. Analysis of glutathione: Implication in redox and detoxification. Clin Chim Acta, 2003; 333: 19-39.

12. Guo, N., Mclntosh, C., and Shaw, C. Glutathione: New candidate neuropeptide in the central nervous system. Neuroscience, 1992; 51(4): $835-842$.

13. Zangerle, L, Cuenod, M, Winterhalter, $\mathrm{KH}$, et al. Screening of thiol compounds: Depolarization-induced release of glutathione and cysteine from rat brain slices. J Neurochem, 1992; 59(1): 181-189.

14. Evans, HM and Bishop, KS. Fetal resorption. Sciences, 1922; 55: 650-652.

15. Colombo, ML. An update on vitamin E, tocopherol and tocotrienolperspectives. Molecules, 2010; 15: 2103-2113.

16. Wang, XY and Quinn, PJ. Vitamin E and its function in membranes. Prog Lipid Res, 1999; 38: 309-336.

17. Robert, E and Olson, MD. Vitamin E and its relation to heart disease. Circulation, 1973; 48: 179-184.

18. Burton, GW, Joyce, A and Incold, KU. Is vitamin E the only lipid-soluble, chain-breaking antioxidant in human blood plasma and erythrocyte membranes? Arch Biochem Biophys, 1982; 221(1): 281-290.

19. Ingold, $\mathrm{KU}, \mathrm{Webb}, \mathrm{AC}$, Witter, $\mathrm{D}$, et al. Vitamin $\mathrm{E}$ remains the major lipidsoluble, chain-breaking antioxidant in human plasma even in individuals suffering severe vitamin E deficiency. Arch Biochem Biophys, 1987; 259(1): 224-225

20. Niki, E. Lipid antioxidants: How they may act in biological systems. $\mathrm{Br}$ Cancer, 1987; 55: 153-157.

21. Laplante, P, Vanasse, M, Michaud, J, et al. A progressive neurological syndrome associated with an isolated vitamin E deficiency. Can J Neuro Sci, 1984: 11(4): 561-564.

22. Stumpf, DA, Sokol, R, Bettis, D, et al. Friedreich's disease: V.variant form with vitamin E deficiency and normal fat absorption. Neurology, 1987, 37(1): $68-74$

23. Ouahchi, K, Arita, M, Kayden, H, et al. Ataxia with isolated vitamin E deficiency is caused by mutations in the $\alpha$-tocopherol transfer protein. Nat Rev Genet, 1995; 9: 141-145.

24. Azzi, A, Aratri, E, Boscoboinik, D, et al. Molecular basis of alphatocopherol control of smooth muscle cell proliferation. BioFactors, 1998; 7(1-2): 3-14.

25. Moslemi, MK and Tavabakhsh, S. Selenium-vitamin E supplementation in infertile men: Effects on semen parameters and pregnancy rate. Int J Gen Med, 2011; 4: 99-104.

26. Sen, CK, Khanna, S, Roy, S, et al. Tocotrienol potently inhibits glutamateinduced pp60c-Src kinase activation and death of HT4 neuronal cells. J Biol Chem, 2000; 275: 13049-13055.

27. Bendich, A, Gabriel, E and Machlin, LJ. Dietary vitamin E requirement for optimum immune responses in the rat. J Nutr, 1986; 116(4): 675-681.

28. Traber, MG. Vitamin E. In M.E. Shils, M. Shike, A.C. Ross, B. Caballero, R.J. Robert. Modern Nutrition in Health and Disesase, 2006; $10^{\text {th }}$ Edition (pp 396-411). Philadelphia: Lippincott Williams \& Wilkins.

29. Fechner, H, Schlame, M, Guthmann, F, et al. $\alpha$-and $\delta$-tocopherol induce expression of hepatic $\alpha$-tocopherol-transfer-protein mRNA. J Biochem, 1998; 331: $577-581$.

30. Hosomi, A, Arita, M, Sato Y, et al. Affinity for $\alpha$-tocopherol transfer protein as a determinant of the biological activities of vitamin E analogs. FEBS, 1997; 409: 105-108.

31. Herrera, E and Barbas, C. Vitamin E: Action, metabolism and perspectives. J Physiol Biochem, 2001; 57(2): 43-56.

32. Zingg, JM and Azzi, A. Significance of the $\alpha$-tocopherol salvage pathway. In T. Grune. Free radicals and disease: Gene expression, cellular metabolism and pathophysiology. 2005; (pp. 113-136). Netherlands: IOS Press.

33. Viola, V, Pilolli, F, Piroddi, M, et al. Why tocotrienols work better: Insights into the in vitro anti-cancer mechanism of vitamin E. Genes Nutr, 2012; 7(1) $29-41$

34. Traber. MG and Kayden, HJ. Vitamin E is delivered to cells via the high affinity receptor for low-density lipoprotein. Am J Clin Nutr, 1984; 40(4): 747-751.

35. Traber, MG, Olivecrona, T and Kayden, HJ. Bovine milk lipoprotein lipase transfers tocopherol to human fibroblasts during triglyceride hydrolysis in vitro. Am Soc Clin Invest, 1985; 75 (5): 1729-1734.

36. Tall, AR and Lalanne, F. Phospholipid transfer protein and atherosclerosis. Arterioscler Thromb, 2003; 23: 1484-1485.

37. Gee, PT. Unleashing the untold and misunderstood observations on vitamin E. Genes Nutr, 2011; 6(1): 5-16.

38. Kagan, VE and Tyurina, YY. Recycling and redox cycling of phenolic antioxidants. Ann N Y Acad Sci, 1998; 854(1): 425-434.

39. Combs, GF and Scott, ML. Nutritional interrelationships of vitamin E and selenium. BioScience, 1977; 27(7): 467-473.

40. Evans, HM, Emerson, $\mathrm{OH}$ and Emerson, GA. Isolation from wheat germ oil of an alcohol, $\alpha$-tocopherol, having the properties of vitamin E. J Biol Chem, 1936; 113(1): 319-332.

41. Packer, L, Weber, SU, and Rimbach, G. Molecular aspects of $\alpha$-tocotrienol antioxidant action and cell signaling. J Nutr, 2001; 131(2): 3695-3735.

42. Upadhyay, $\mathrm{J}$ and Misra, $\mathrm{K}$. Towards the interaction mechanism of tocopherols and tocotrienols (vitamin E) with selected metabolizing enzymes. Bioinformation, 2009; 3(8): 326-331.

43. Freedman, JE, Farhat, JH, Loscalzo, J, et al. Alpha-tocopherol inhibit aggregation of human platelets by a protein kinase C-dependent mechanism. Circulation, 1996: 94(10): 2434-2440.

44. Osakada, F, Hashino, A, Kume, T, et al. Neuroprotective effects of alphatocopherol on oxidative stress in rat striatal cultures. Eur J Pharmacol, 2003; 465 (1-2): 15-22.

45. Devaraj, S and Jialal, L. Alpha-tocopherol decreases interleukin-1 beta release from activated human monocytes by inhibition of 5-lipoxygenase. Arterioscler Thromb, 1999; 19(4): 1125-1133.

46. Aggarwal, BB, Sundaram, C, Prasad, S, et al. Tocotrienols, the vitamin E of the $21^{\text {st }}$ century: Its potential against cancer and other chronic diseases. Biochem Pharmacol, 2010; 80(11): 1613-1631.

47. Packer, L, Kraemer, K and Rimbach, G. Molecular aspects of lipoic acid in the prevention of diabetes complications. Nutrition, 2001; 17(10): 888-895.

48. Suzuki, YJ, Tsuchiya, M, Wassall, SR, et al. Structural and dynamic membrane properties of $\alpha$-tocopherol and $\alpha$-tocotrienol: Implication to the molecular mechanism of their antioxidant potency. Biochemistry, 1993; 32: 1069210699.

49. Serbinova, B, Kagan, Y, Han, D, et al. Free radical recycling and intramembrane mobility in the antioxidant properties of alpha-tocopherol and alpha-tocotrienol. Free Radic Biol Med, 1991; 10: 263-275.

50. Yoshida, Y, Niki, E and Noguchi, N. Comparative study on the action of tocopherols and tocotrienols as antioxidant: Chemical and physical effects. Chem Phys Lipids, 2003; 123: 63-75.

51. Kamat, JP and Devasagayam, TPA. Tocotrienols from palm oil as potent inhibitors of lipid peroxidation and protein oxidation in rat brain mitochondria. Neurosci Lett, 1995; 195(3): 179-182.

52. Mutalib, MSA, Khaza'ai, H and Wahle, KWJ. Palm-tocotrienol rich fraction (TRF) is a more effective inhibitor of LDL oxidation and endothelial cell lipid peroxidation than $\alpha$-tocopherol in vitro. Food Res Int, 2003; 36(5): 405-413.

53. Osakada, F, Hashino, A, Kume, T, et al. A-tocotrienol provides the mos potent neuroprotection among vitamin $\mathrm{E}$ analogs on cultured striatal neurons. Neuropharmacology, 2004; 47: 904-915.

54. Khanna, S, Roy, S, Ryu, H, et al. Molecular basis of vitamin E action Tocotrienol modulates 12-lipoxygenase, a key mediator of glutamate-induced neurodegeneration. J Biol Chem, 2003; 278(44): 43508-43515.

55. Khanna, S, Parinandi, NL, Kotha, SR, et al. Nanomolar vitamin E $\alpha$-tocotrienol inhibits glutamate-induced activation of phospholipase A2 and causes neuroprotection. J Neurochem, 2010; 112(5): 1249-1260.

56. Ser, H-L, Tan, LT-H, Law, JW-F, et al. Focused review: cytotoxic and antioxidant potentials of mangrove-derived Streptomyces. Front Microbiol, 2017; 8: 2065.

57. Law, JW-F, Ser, H-L, Ab Mutalib, N-S, et al. Streptomyces monashensis sp. nov., a novel mangrove soil actinobacterium from East Malaysia with antioxidative potential. Sci Rep, 2019; 9(1): 3056

58. Ser, H-L, Tan, W-S, Ab Mutalib, N-S, et al. Draft genome sequence of mangrove-derived Streptomyces sp. MUSC 125 with antioxidant potential. Front Microbiol, 2016; 7: 1470

59. Tan, LTH, Mahendra, CK, Yow, YY, et al Streptomyces sp MUM273b: A 
mangrove $\square$ derived potential source for antioxidant and UVB radiation protectants. MicrobiologyOpen, 2019: e859.

60. Ser, H-L, Yin, W-F, Chan, K-G, et al. Antioxidant and cytotoxic potentials of Streptomyces gilvigriseus MUSC $26^{\mathrm{T}}$ isolated from mangrove soil in Malaysia. Prog Microbes Mol Biol, 2018; 1(1): a0000002.

61. Law, JW-F, Chan, K-G, He, Y-W, et al. Diversity of Streptomyces spp. from mangrove forest of Sarawak (Malaysia) and screening of their antioxidant and cytotoxic activities. Sci Rep, 2019; 9(1): 1-15.

62. Ser, H-L, Palanisamy, UD, Yin, W-F, et al. Presence of antioxidative agent, Pyrrolo [1, 2-a] pyrazine-1, 4-dione, hexahydro-in newly isolated Streptomyces mangrovisoli sp. nov. Front Microbiol, 2015; 6: 854.

63. Lee, L-H, Zainal, N, Azman, A-S, et al. Streptomyces pluripotens sp. nov., a bacteriocin-producing streptomycete that inhibits meticillin-resistant Staphylococcus aureus. Int J Syst Evol Microbiol, 2014; 64(9): 32973306.

64. Ser, H-L, Tan, W-S, Ab Mutalib, N-S, et al. Genome sequence of Streptomyces pluripotens MUSC $135^{\mathrm{T}}$ exhibiting antibacterial and antioxidant activity. Mar Genomics, 2015; 24: 281-283.

65. Ser, H-L, Ab Mutalib, N-S, Yin, W-F, et al. Genome sequence of Streptomyces antioxidans MUSC $164^{\mathrm{T}}$ isolated from mangrove forest. Prog Microbes Mol Biol, 2018; 1(1): a0000001.

66. Ser, H-L, Chan, K-G, Tan, W-S, et al. Complete genome of mangrovederived anti-MRSA streptomycete, Streptomyces pluripotens MUSC 135 . Prog Microbes Mol Biol, 2018; 1(1): a0000004

67. Ser, H-L, Tan, LT-H, Palanisamy, UD, et al. Streptomyces antioxidans sp. nov., a novel mangrove soil actinobacterium with antioxidative and neuroprotective potentials. Front Microbiol, 2016; 7: 899.

68. Lee, L-H, Chan, K-G, Stach, J, et al. The search for biological active agent (s) from actinobacteria. Front Microbiol, 2018; 9: 824.

69. Ser, H-L, Palanisamy, UD, Yin, W-F, et al. Streptomyces malaysiense sp. nov.: A novel Malaysian mangrove soil actinobacterium with antioxidative activity and cytotoxic potential against human cancer cell lines. Sci Rep, 2016; 6(1): 1-12.

70. Law, JW-F, Pusparajah, P, Ab Mutalib, N-S, et al. A review on mangrove actinobacterial diversity: The roles of streptomyces and novel species discovery. Prog Microbes Mol Biol, 2019; 2(1): a00000024.

71. Azman, A-S, Othman, I, Fang, C-M, et al. Antibacterial, anticancer and neuroprotective activities of rare Actinobacteria from mangrove forest soils. Indian J Microbiol, 2017; 57(2): 177-187.

72. Law, JW-F, Letchumanan, V, Tan, LT-H, et al. The rising of "Modern Actinobacteria" Era. Prog Microbes Mol Biol, 2020; 3(1): a00000064.

73. Tan, LT-H, Chan, K-G, Khan, TM, et al. Streptomyces sp. MUM212 as a source of antioxidants with radical scavenging and metal chelating properties. Front Pharmacol, 2017; 8: 276.

74. Kemung, HM, Tan, LT-H, Chan, K-G, et al. Investigating the antioxidant potential of Streptomyces sp. MUSC 11 from mangrove soil in Malaysia. Prog Drug Discov Biomed Sci, 2019; 2(1).

75. Tan, LT-H, Chan, K-G, Chan, CK, et al. Antioxidative potential of a Streptomyces sp. MUM292 isolated from mangrove soil. Biomed Res Int, 2018; 2018: 4823126

76. Kemung, HM, Tan, LT-H, Chan, K-G, et al. Antioxidant activities of Streptomyces sp. strain MUSC 14 from mangrove forest soil in Malaysia. Biomed Res Int, 2020: 6402607

77. Tan, LT-H, Ser, H-L, Yin, W-F, et al. Investigation of antioxidative and anticancer potentials of Streptomyces sp. MUM256 isolated from Malaysia mangrove soil. Front Microbiol, 2015; 6: 1316.

78. Law, JW-F, Ser, H-L, Duangjai, A, et al. Streptomyces colonosanans sp. nov., a novel actinobacterium isolated from Malaysia mangrove soil exhibiting antioxidative activity and cytotoxic potential against human colon cancer cell lines. Front Microbiol, 2017; 8: 877.

79. Tan, LT-H, Chan, K-G, Pusparajah, P, et al. Mangrove derived Streptomyces sp. MUM265 as a potential source of antioxidant and anticolon-cancer agents. BMC Microbiol, 2019; 19(1): 38
80. Ser, H-L, Ab Mutalib, N-S, Yin, W-F, et al. Evaluation of antioxidative and cytotoxic activities of Streptomyces pluripotens MUSC 137 isolated from mangrove soil in Malaysia. Front Microbiol. 2015; 6: 1398

81. Argarwal, MK, Agarwal, ML, Athar, M, et al. Tocotrienol-rich fraction of palm oil activates $\mathrm{p} 53$, modulates $\mathrm{Bax} / \mathrm{Bcl} 12$ ratio and apoptosis independent of cell cycle association. Cell Cycle, 2004; 3(2): 205-211.

82. Sakai, M, Okabe, M, Tachibana, $\mathrm{H}$, et al. Apoptosis induction by gammatocotrienol in human hepatoma Hep3B cells. J Nutri Biochem, 2006; 17(10): 672-676.

83. Srivastava, JK and Gupta, S. Tocotrienol-rich fraction of palm oil induces cell cycle arrest and apoptosis selectively in human prostate cancer cells Biochem Biophys Res Commun, 2006; 346(2): 447-453.

84. Kashiwagi, K, Harada, K, Yano, Y, et al. A redox-silent analogue of tocotrienol inhibits hypoxic adaptation of lung cancer cells. Biochem Biophys Res Commun, 2008; 365(4): 875-881.

85. Sun, W., Wang, Q, Chen, B, et al. Gamma-tocotrienol-induced apoptosis in human gastric cancer SGC-7901 cells is associated with a suppression in mitogen-activated protein kinase signaling. Br J Nutr, 2008; 99(6): $1247-$ mitog 1254 .

86. Chang, PN, Yap, WN, Lee, DT, et al. Evidence of gamma-tocotrienol as an apoptosis-inducing, invasion-suppressing, and chemotherapy drugsensitizing agent in human melanoma cells. Nutr Cancer, 2009; 61(3): sensitizing 365 .

87. Hussein, D and Mo, H. Delta-tocotrienol-mediated suppression of the proliferation of human PANC-1, MIA PaCa-2, and BxPC-3 pancreatic carcinoma cells. Pancreas, 2009; 38(4): 124-136.

88. Guthrie, N, Gapor, A, Chambers, AF, et al. Inhibition of proliferation of estrogen receptor-negative MDA-MB-435 and -positive MCF-7 breast cancer cells by palms oil tocotrienols and tamoxifen, alone and in combinations. $J$ Nutri, 1997; 127(3): 544-548.

89. Nesaretnam, K, Stephen, R, Dils, R, et al. Tocotrienols inhibit the growth of human breast cancer cells irrespective of estrogen receptor status. Lipids, 1998; 33(5): 461-460.

90. Parker, A, Pearce, BC, Clark, RW, et al. Tocotrienols regulate cholesterol production in mammalian cells by post-transcriptional suppression of 3-hydroxy-3-methylglutaryl-coenzyme A reductase. J Biol Chem, 1993; 268: $11230-11238$.

91. Chao, JT, Gapor, A and Theriault, A. Inhibitory effect of $\delta$-tocotrienol, a HMG CoA reductase inhitor, on monocyte-endothelial cell adhesion. J Nutr Sci Vitaminol, 2002; 48(5): 332-337.

92. Goldberg, MP and Choi, DW. Combined oxygen and glucose deprivation in cortical cell culture: Calcium-dependent and calcium-independent mechanisms of neuronal injury. J Neurosci, 1993; 13(8): 3510-3524.

93. Steinberg, R, Gueniau, C, Scarna, H, et al. Experimental brain ischemia: Neuron-specific enolase level in cerebrospinal fluid as an index of neuronal damage. J Neurochem, 1984; 43(1): 19-24.

94. Lamers, KJB, Vos, P, Verbeek, MM, et al. Protein S-100B, neuron-specific enolase (NSE), myeline basic protein (MBP) and glial fibrillary acidic protein (GFAP) in cerebrospinal fluid (CSF) and blood of neurological patients. Brain Res Bull, 2003; 61: 261-264.

95. Pelinka, LE, Hertz, H, Mauritz, W, et al. Nonspecific increase of systemic neuron-specific enolase after trauma: Clinical and experimental findings. Shock, 2005; 24(2): 119-123.

96. Gross, J, Unqethum, U, Andreeva, $\mathrm{N}$, et al. Glutamate-induced efflux of protein, neuron-specific enolase and lactate dehydrogenase from a mesencephalic cell culture. Eur J Clin Chem Clin Biochem, 1996; 34(4) $305-310$.

97. Bonora, M, Patergnani, S, Rimessi, A, et al. ATP synthesis and storage. Purinergic Signalling, 2012; 8: 343-357.

98. Berger, RP, Pierce, MC, Wisniewski, SR, et al. Neuron-specific enolase and $\mathrm{S} 100 \mathrm{~B}$ in cerebrospinal fluid after severe traumatic brain injury in infants and children. Pediatrics, 2002; 109(2): e31. 